\title{
Computation of Isobaric Vapor-Liquid Equilibrium Data for Binary and Ternary Mixtures of Methanol, Water, and Ethanoic Acid from $T, p, x$, and $H_{m}^{E}$ Measurements
}

\author{
Daming Gao, 1, 2 Hui Zhang, 1, 2 Peter Lücking, 2, 3 Hong Sun, , 2 Jingyu Si, \\ Dechun Zhu, ${ }^{1,2}$ Hong Chen, ${ }^{1}$ and Jianjun Shi ${ }^{1,2}$ \\ ${ }^{1}$ Department of Chemistry and Materials Engineering, Hefei University, Anhui, Hefei 230022, China \\ ${ }^{2}$ Sino-German Research Center for Process Engineering and Energy Technology, Anhui, Hefei 230022, China \\ ${ }^{3}$ Department of Engineering, Jade University of Applied Science, 26389 Wilhelmshaven, Germany \\ Correspondence should be addressed to Daming Gao, dmgao@hfuu.edu.cn
}

Received 25 March 2012; Revised 5 August 2012; Accepted 5 August 2012

Academic Editor: Ahmet Z. Sahin

Copyright ( 2012 Daming Gao et al. This is an open access article distributed under the Creative Commons Attribution License, which permits unrestricted use, distribution, and reproduction in any medium, provided the original work is properly cited.

\begin{abstract}
Vapor-liquid equilibrium (VLE) data for the strongly associated ternary system methanol + water + ethanoic acid and the three constituent binary systems have been determined by the total pressure-temperature-liquid-phase composition-molar excess enthalpy of mixing of the liquid phase $\left(p, T, x, H_{m}^{E}\right)$ for the binary systems using a novel pump ebulliometer at $101.325 \mathrm{kPa}$. The vapor-phase compositions of these binary systems had been calculated from $T p x$ and $H_{m}^{E}$ based on the $Q$ function of molar excess Gibbs energy through an indirect method. Moreover, the experimental $T, x$ data are used to estimate nonrandom twoliquid (NRTL), Wilson, Margules, and van Laar model parameters, and these parameters in turn are used to calculate vapor-phase compositions. The activity coefficients of the solution were correlated with NRTL, Wilson, Margules, and van Laar models through fitting by least-squares method. The VLE data of the ternary system were well predicted from these binary interaction parameters of NRTL, Wilson, Margules, and van Laar model parameters without any additional adjustment to build the thermodynamic model of VLE for the ternary system and obtain the vapor-phase compositions and the calculated bubble points.
\end{abstract}

\section{Introduction}

New strategies for the correlation and accurate prediction of the vapor-liquid equilibrium (VLE) data play a vital role in the distillation and separation process in chemical industry. The common technique for obtaining VLE data is by direct measurement on the system. That is to say, when the VLE is established, and phases are sampled and analyzed. Consequently, the experimental technique must be rather highly accurate to ensure meaningful results in the operation of equilibrium stills. Actually, when the vapor-phase components are sampled and analyzed, the whole compositions of components in solution and vapor have been changed. Accordingly, the behavior of the systems has been changed with the amount of compositions. Moreover, it has been long realized that the analysis of vapor-liquid composition for the infinite dilute solution is very difficult. In addition, for VLE measurements of mixtures containing a highly volatile compound, the accurate measurement of the vapor-phase composition can be difficult. This fact, coupled with the necessity for much analytical work, tends to enhance interest in exploring new methods for the determination of equilibrium data that do not involve sampling and analysis of the vaporphase components.

Several methods have been explored for the calculation of component behavior from gross solution behavior. Van Ness and coworkers have suggested the classification of these methods into two categories, direct and indirect methods [1]. The direct methods involve calculation of vapor compositions by integration of the coexistence equation, a firstorder differential equation derived from the Gibbs-Duhem equation relating phase compositions at equilibrium. Hala and coworkers have given a detailed discussion of the basic direct method [2], and Van Ness and coworkers have 
discussed techniques for handling nonconstant temperature or pressure conditions as well as nonideal vapor phase behavior [1, 3]. Moreover, in the total pressure method one can calculate $y$ from $T, p, x$ measurements using an indirect method discussed by Mixon et al. [4].

Of all the methods, the indirect methods involve first the measurement, by some appropriate means, the temperature and total pressure of the system, the liquid-phase compositions, and subsequent calculation of vapor-phase compositions there from. These methods usually involve ascertaining which of selected solution equations to the Gibbs-Duhem equation lead to the best fit to the experimental data, and of the determination of the parametric values producing the best fit. For example, Barker has developed a procedure based on the assumption that the excess free energy can be represented as a polynomial function of composition [5].

There is a basic difference in the degree of rigor associated with the direct method and the indirect method of Barker. In the former, one makes no assumptions about the solution behavior for the nature of molecular interactions. Solution behavior is determined directly from the experimental data. The Barker method necessitates the assumption of a particular model and the estimation of its parameters, this deficiency in the method of Barker has been recognized by Tao, who has presented another indirect method in which the necessity for the a priori assumption of a particular functional form for the excess free energy has been removed. Tao's procedure involves calculation of the activity coefficient essentially by integration of an equation resembling the coexistence equation. His procedure, though indirect, retains the rigor usually associated with the direct method [6]. The method of Tao appears specific to binary systems and does not seem to be easily generalized. However, an indirect method such as that of Barker is readily and easily generalized to ternary and higher-ordered systems, but this method retains the disadvantage of lacking rigor as compared with the direct method.

This paper presents the vapor-liquid compositions calculated based on the measurements of VLE data for temperature-total pressure-liquid-phase composition-molar excess enthalpy energy of mixing of the liquid phase $(T$, $\left.p, x, H_{m}^{E}\right)$ at $101.325 \mathrm{kPa}$ according to the $Q$ function of molar excess Gibbs energy through an indirect method. We know that the reaction of methanol carboxylated with carbon monoxide is the most common and important technology for synthesis of ethanoic acid in the chemical industrial process. Modeling the thermodynamic properties and correlating and predicting the phase equilibria of a mixture involving associating components forming hydrogen bonding such as carboxylic acid remain a challenging problem, since such systems show extremely nonideal behavior and the formation of monomer, dimer, and even trimer in vapor and liquid phase. In addition, for the VLE measurements of vaporphase components containing a highly volatile compound such as carboxylic acid, the accurate measurement of the vapor-phase composition can be difficult. Many attempts have been made to describe the vapor-liquid equilibria of carboxylic acid containing mixtures using the concept of multiscale association [7]. Arlt reported the isothermal VLE data of a new apparatus for phase equilibria in reaction mixtures containing water with ethanoic acid and propanoic acid at (333 to 363) K [8]. Xu and Chuang have developed a new correlation for the prediction of the vapor-liquid equilibrium of methyl acetate-methanol-water-ethanoic acid mixtures [9]. Sawistowski and Pilavakis explored the vaporliquid equilibrium behavior of the quaternary system methyl acetate-methanol-water-ethanoic acid modeled by using the Margules equation in combination with Marek's method for the association of ethanoic acid [10]. Moreover, Guan et al. investigated that the isobaric vapor-liquid equilibria for water + ethanoic acid + n-pentyl acetate, isopropyl acetate, $N$-methyl pyrrolidone, or $N$-methyl acetamide were correlated and predicted by both the nonrandom two-liquid (NRTL) and universal quasichemical activity coefficient (UNIQUAC) models used in combination with the HaydenO'Connell (HOC) method [11-14]. In our recent work, we have concluded that the VLE data for the associating systems containing the carboxylic acid system can be correlated and predicted $[15,16]$. Although the VLE data of the mixture containing the associating systems were previously reported by the different research groups [17-21], respectively, the VLE data for the associating binary system containing the carboxylic acid have been still extensively studied because of the extensive association effects occurring in them and the difficulty of properly calculating the activity coefficients [22-25]. Nominally, the system is binary but in practice, it is multicomponent. Because the carboxylic acid monomer undergoes partial dimerization and even higher polymerization. This association is attributed to the formation of hydrogen bonds and occurs in both the vapor and liquid phase. Therefore, the challenge for the VLE data of the associating systems has evoked more and more researchers to focus on new strategies for exploring them. The VLE data for methanol + water + ethanoic acid ternary system and the constituent binary systems are indispensable in distillation separation process to the product of methanol carboxylation through the correlation and prediction by the new method, while some of the isobaric VLE data for these binary and ternary systems are correlated and predicted earlier [9-25]. To provide the new correlation and prediction for some necessary basic thermodynamic data on the separation process of methanol carboxylation, therefore, it is very indispensable for these systems studied on the VLE data of the constituent binary and ternary systems using the new method. This paper reports a novel correlation and prediction for the VLE data for these systems containing the associating component that has been developed. The VLE data for methanol + water + ethanoic acid system and constituent binary systems were measured by the total pressure-temperature-liquid-phase composition-molar excess enthalpy of mixing of the liquid phase $\left(p, T, x, H_{m}^{E}\right)$ for the binary systems using the novel pump-ebulliometer at $101.325 \mathrm{kPa}$. Owing to the association of ethanoic acid molecules, Marek's method in combination with Hayden-O'Connell (HOC) model was used to deal with the associating properties of the liquid and vapor phase and the nonideality of vapor phase, respectively [26-28]. However, the nonideality of liquid phase was corrected by the calculation of its activity coefficient, which was obtained 
based on NRTL, Wilson, Margules, and van Laar models as the function of $T, x$ through the nonlinear fit of the least-squares method. NRTL, Wilson, Margules, and van Laar models were applied to correlate the VLE data for the three constituent binary systems, and the model parameters together with the deviations of temperature and vaporphase molar fractions calculated from $T, p, x, H_{m}^{E}$ according to the $Q$ function of molar excess Gibbs energy by the indirect method were obtained by the least-squares method. The VLE data of the ternary system were well predicted from these binary interaction parameters of NRTL, Wilson, Margules, and van Laar models without any additional adjustment to build the thermodynamic model of VLE for the ternary system and obtain the vapor-phase compositions and the calculated bubble points. The excess Gibbs free energies for these binary systems as the function of liquidphase composition and activity coefficient were calculated through the activity coefficient correlation to NRTL model parameters with the experimental data.

\section{Modeling Section}

There is an added complexity when working with carboxylic acids because they associate in the vapor and liquid phases. This association can be represented by assuming that the organic acid exists as monomer and dimer according to the Marek's method [26, 27]. This fact, coupled with the necessity for much analytical work, tends to enhance interest in exploring the new strategies for correlation and prediction of the VLE data for the systems containing the associating carboxyl acid.

According to the Marek's chemical theory, there are monomer and dimer carboxylic acid molecules in both liquid and vapor phases. The equilibrium constant of vapor-phase dimerization, $C_{E}^{V}$, is calculated by the expression

$$
C_{E}^{V}=\frac{y_{D}^{*}}{\left(y_{M}^{*}\right)^{2} p}
$$

and the equilibrium constant of liquid-phase dimerization, $C_{E}^{L}$, is calculated by the expression

$$
C_{E}^{L}=\frac{x_{D}^{*}}{\left(x_{M}^{*}\right)^{2}} .
$$

In equations mentioned above, $y_{D}^{*}$ and $x_{D}^{*}$ are the mole fractions of dimers of ethanoic acid molecules in both vapor and liquid phases, respectively, and $C_{E}^{V}$ can be defined as the function of temperature by the expression obtained from the literature [27]

$$
C_{E}^{V}=\exp \left(\frac{7290}{T}-21.980\right),
$$

where $C_{E}^{V}$ was presented in $\mathrm{kPa}^{-1}$ and $T$ in $\mathrm{K}$.

When the dimers of ethanoic acid molecules mainly exist, the binary system for the methanol or water (1) + ethanoic acid (2) is nominally binary; however, it is actually ternary for the methanol or water $(1)+$ monomer ethanoic acid $(M)+$ dimer ethanoic acid $(D)$ system. In this system, the mole fractions of vapor-liquid equilibrium phases are $y_{1}^{*}$, $y_{M}^{*}, y_{D}^{*}, x_{1}^{*}, x_{M}^{*}$, and $x_{D}^{*}$, respectively. Therefore, the VLE relations of the nonassociating and associating components are individually calculated by the expressions

$$
\begin{aligned}
p y_{1}^{*} \Phi_{1} & =p_{1}^{s} x_{1}^{*} \gamma_{1}, \\
p y_{M}^{*} \Phi_{M} & =p_{M}^{s} x_{M}^{*} \gamma_{M}, \\
p y_{D}^{*} \Phi_{D} & =p_{D}^{s} x_{D}^{*} \gamma_{D} .
\end{aligned}
$$

In (4), the actual mole fractions can be denoted by the apparent mole fractions of easily determined components $\left(y_{1}, y_{2}, x_{1}\right.$, and $x_{2}$ multiplied by a modified coefficient. Likewise, the measured apparent vapor pressure saturated of ethanoic acid $\left(p_{2}^{s}\right)$ multiplied by a modified coefficient can also denote the actual vapor pressures saturated of monomer and dimer ethanoic acid $\left(p_{M}^{s}, p_{D}^{s}\right)$. Consequently, the apparent compositions and vapor pressures saturated substitute for the actual ones, and the VLE relation of the nonassociating component, methanol or water (1), is expressed by

$$
p y_{1} \alpha_{1} \Phi_{1}=p_{1}^{s} x_{1} \beta_{1} \gamma_{1}
$$

where

$$
\begin{gathered}
\alpha_{1}=\frac{2}{\left(2-y_{2}\right)} \frac{1-y_{2}-\sqrt{1+4 C_{E}^{V} p y_{2}\left(2-y_{2}\right)}}{1+\sqrt{1+4 C_{E}^{V} p y_{2}\left(2-y_{2}\right)}}, \\
\beta_{1}=\frac{2}{\left(2-x_{2}\right)} \frac{1-x_{2}-\sqrt{1+4 C_{E}^{L} p x_{2}\left(2-x_{2}\right)}}{1+\sqrt{1+4 C_{E}^{L} p x_{2}\left(2-x_{2}\right)}},
\end{gathered}
$$

and for ethanoic acid (2), which is the associating component, its relation is expressed by

$$
p y_{2} \alpha_{2} \Phi_{2}=p_{2}^{s} \theta_{2}^{s} x_{2} \beta_{2} \gamma_{2},
$$

where

$$
\begin{gathered}
\alpha_{2}=\frac{2}{1+\sqrt{1+4 C_{E}^{V} p y_{2}\left(2-y_{2}\right)}}, \\
\beta_{2}=\frac{2}{1+\sqrt{1+4 C_{E}^{L} x_{2}\left(2-x_{2}\right)}}, \\
\theta_{2}^{s}=\frac{-1+\sqrt{1+4 C_{E}^{V} p_{2}^{s}}}{2 C_{E}^{V} p_{2}^{s}} .
\end{gathered}
$$

In (5) to (11), $\alpha_{1}$ and $\alpha_{2}$ can be regarded as modified coefficients for the deviation from ideality in vapor phase on account of association. The fugacity of coefficients $\Phi_{1}$ and $\Phi_{2}$ is not negligible, and their values were obtained through the HOC model [28]. From another point of view, $\theta_{2}^{s}$ can be viewed as a modified coefficient for the vapor pressure of the associating component. Moreover, $\beta_{1}$ and $\beta_{2}$ denote modified coefficients of the deviation from ideality in the liquid phase by reason of the existence of association, and $\gamma_{1}$ and $\gamma_{2}$ express the deviation from ideality in liquid 
TABLE 1: Physical properties of the pure compounds: densities $\rho$, refractive indexes $n_{D}$ at $298.15 \mathrm{~K}$ and normal boiling points $T_{b}$.

\begin{tabular}{lcccccc}
\hline Compound & \multicolumn{2}{c}{$\rho / \mathrm{kg} \cdot \mathrm{m}^{-3}$} & & $n_{D}$ & & $T_{b} / \mathrm{K}$ \\
& expt & lit $^{\mathrm{a}}$ & expt & lit $^{\mathrm{a}}$ & & expt $^{\mathrm{a}}$ \\
\hline Methanol & 786.44 & 786.37 & 1.3264 & 1.3265 & 337.71 & 337.69 \\
Water & 997.01 & 997.05 & 1.3324 & 1.3325 & 373.16 \\
Ethanoic acid & 1043.90 & 1043.92 & 1.3716 & 1.3718 & 391.53 & 391.15 \\
\hline
\end{tabular}

${ }^{a}$ Riddick et al. [29].

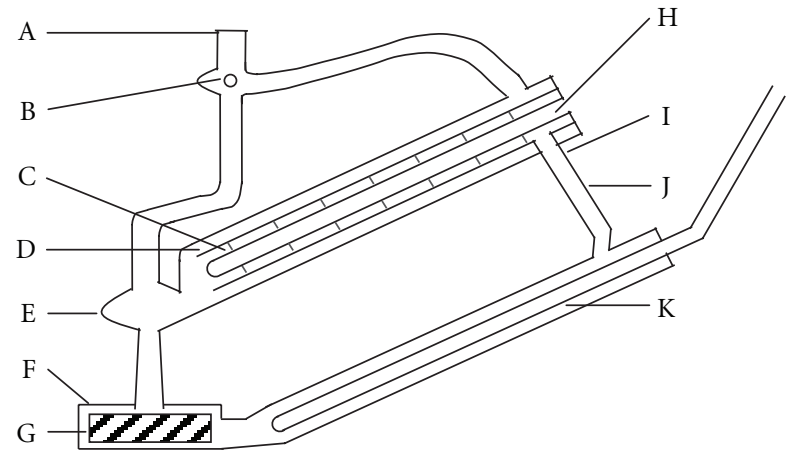

Figure 1: Schematic illustration for the structure of pump ebulliometer. (A) Normal distilling adaptor; (B) feed inlet; (C) coiled glass thread; (D) constant temperature introducing tube; (E) mixed vial section; (F) magnetic recirculating bump; (G) magnetic stirrer; ( $\mathrm{H})$ measured thermowell (filled with conducting oil); (I) tube window to observe in VLE status; ( $\mathrm{J}$ ) internal heating tube; $(\mathrm{K})$ partheating tube (resistance heating wire inserted).

phase because of other factors. Herein, in liquid phase, the modified coefficients of deviation from ideality, $\beta_{1}$ and $\beta_{2}$, can be incorporated to the activity coefficients, $\gamma_{1}$ and $\gamma_{2}$, respectively. So (5) and (8) are obtained by the expressions

$$
\begin{gathered}
p y_{1} \alpha_{1} \Phi_{1}=p_{1}^{s} x_{1} \gamma_{1}, \\
p y_{2} \alpha_{2} \Phi_{2}=p_{2}^{s} \theta_{2}^{s} x_{2} \gamma_{2} .
\end{gathered}
$$

\section{Experimental Section}

3.1. Materials. Methanol ( 99.8 mass \%) and ethanoic acid (99.8 mass \%) were purchased from Sigma. The purities of the chemicals are provided by the manufacture's specifications. Ultra sound was used to dispel the solvent air in the materials, which were dried on molecular sieve (pore diameter $30 \mathrm{~nm}$ from Fluka) to remove all possible traces of moisture before use, but no other treatments were applied. The densities and refractive indices at $298.15 \mathrm{~K}$ and normal boiling points at $101.325 \mathrm{kPa}$ of the pure component were compared with the literature values of Riddick et al. [29]. The results show that the measured values are approximately in agreement with those of the literature, as presented in Table 1. The measurement method of the composition dependence of densities and refractive indices has been previously reported [30].

3.2. Apparatus and Procedure. A new type of magnetic pump ebulliometer described in detail by Qiu et al. [31] was used to measure the boiling points with different liquid phase compositions at the $101.325 \mathrm{kPa}$. The experimental main apparatus for pump-ebulliometer is schematically shown in Figure 1. The recirculation still is entirely constructed from borosilicate glass. The main parts are a magnetic recirculating bump (F), a magnetic stirrer $(\mathrm{G})$, a thermo-well (filled with a conducting oil) provided to enable good measurement of equilibrium temperature $(\mathrm{H})$, a part-heating tube (resistance heating wire inserted) $(\mathrm{K})$, and a tube window to observe in VLE status (I). The apparatus is an all-glass dynamic recirculation still with total volume of about $1.00 \times$ $10^{-4} \mathrm{~m}^{3}$. During the run, to avoid the over heating, the still was submerged in a constant temperature bath at about $3^{\circ} \mathrm{C}$ below the equilibrium boiling point, which was obtained by the Nichrome wire in the part-heating tube $(\mathrm{K})$ to partially heat the known mass of the material. The equilibrium pressure was measured using a Fischer digital manometer with a precision of $\pm 0.01 \mathrm{kPa}$. The pressure measurement for the manometer had an uncertainty of $\pm 0.07 \mathrm{kPa}$, as provided by the manufacturer's specifications. The total uncertainty of calibration and pressure measurement is estimated to be $\pm 0.15 \mathrm{kPa}$ because of the uncertainty of the calibration and measurement errors. Since the barometric pressure changed slightly, the experimental temperatures of the systems were automatically calibrated to that at $101.325 \mathrm{kPa}$ with selfadjusted pressure system. The temperature was measured using a Heraeus QuaT100 quartz thermometer with a thermosensor, with an accuracy of $\pm 0.01 \mathrm{~K}$. The calibration of the thermometers was carried out at the accredited calibration laboratory (Quality and Technique Bureau, Anhui). The total uncertainty of calibration and temperature measurement is evaluated to be $\pm 0.085 \mathrm{~K}$ because of the uncertainty of the calibration, the probe's position, and the pressure fluctuations. The equilibrium temperature, $T$, was measured by means of the thermosensor inserted into the thermowell (filled with conducting oil) $(\mathrm{H})$. In each experiment, a known mass of the material was introduced from the injector into the still from feed inlet (B) and heated to equilibrium boiling point of the system at a fixed pressure of $101.325 \mathrm{kPa}$ by an automatic pressure regulation system. The liquid mixtures of required composition were prepared gravimetrically, with the use of a Sartorius electronic analytic balance (model ER-182A) with an accuracy of $\pm 0.0001 \mathrm{~g}$. The values of mole fraction were reproducible to \pm 0.0001 and have uncertainty of $0.01 \%$. The ebulliometer was charged with the mixture of desired composition, and the boiler was then heated by nichrome wire wound around the boiler. After the liquid mixture started boiling, the bubbles along with the drops of liquid slowly spurted on the 
thermowell one by one through the tube window observed in VLE status (I). When the VLE state was attained by adjusting the pressure to $101.325 \mathrm{kPa}$, it remained constant for $20 \mathrm{~min}$ to ensure the stationary state, and then the boiling temperature was measured.

A flow microcalorimeter (model 2107, LKB produkter, Bromma, Sweden) was applied to measure the molar excess enthalpies, $H_{m}^{E}$, of the mixtures. The electrical-calibration apparatus and its operating procedure have been described elsewhere by Francesconi and Comelli [34]. Two automatic burets (ABU, Radiometer, Copenhagen, Denmark) were used to pump liquids through the mixing cell of the calorimeter. The performance of the calorimeter was checked by measuring the $H_{m}^{E}$ of the test mixture hexane + cyclohexane system reported by Gmehling [35]. Agreement with literature is better than $0.5 \%$ over the central range of mole fraction of hexane.

The uncertainties in mole fraction and $H_{m}^{E}$ are estimated to be 0.0005 and $0.5 \%$, respectively. The liquid-phase mole fraction of component $i, x_{i}$, could be calculated from the known mass of the material added to the still. The vaporphase mole fraction of component $i, y_{i}$, was calculated from the experimental $T, p, x$, and $H_{m}^{E}$ data based on the $Q$ function (the function of molar excess Gibbs energy) by the indirect method.

\section{Results and Discussion}

4.1. Calculation of Vapor-Phase Mole Fraction $y$ for the Binary Systems from $T p x$ and $H_{m}^{E}$. The vapor-phase mole fraction $y_{i}$ of the components was calculated from

$$
y_{i} \Phi_{i} p=x_{i} y_{i} p_{i}^{s}
$$

and the fugacity of coefficients $\Phi_{i}$ of the components was obtained by the expression

$$
\Phi_{i}=\frac{\hat{\varphi}_{i}^{V}}{\varphi_{i}^{s}} \exp \left[-\frac{V_{i}^{L}\left(p-p_{i}^{s}\right)}{R T}\right]
$$

where $\hat{\varphi}_{i}^{V}$ is the fugacity coefficient of component $i$ in the vapor mixture, $\varphi_{i}^{s}$ is the fugacity coefficient of component $i$ at saturation, $V_{i}^{L}$ is the molar volume of component $i$ in the liquid phase, $R$ is the universal gas constant, $T$ is the experimental temperature, $p$ is the total pressure $(101.325 \mathrm{kPa})$, and $p_{i}^{s}$ is the vapor pressure of pure component $i$. The Antoine equations were applied to calculate the values of these vapor pressures. The Antoine constants $A_{i}, B_{i}, C_{i}$, and the values of $T_{c}, p_{c}, V_{c}, Z_{c}$ and $\omega$ were obtained from Shi et al. [36], as shown in Table 2. The Poynting correction factor was also included in the calculation of fugacity at the reference state. The liquid molar volumes were evaluated from the modified Rackett equation [37].

According to the Gibbs-Duhem equation, any extensive molar thermodynamic property of a given phase, such as the Gibbs and Helmholtz energies, the enthalpy, and molar volume, must satisfy the following differential relation:

$$
\left(\frac{\partial M}{\partial T}\right)_{p, x_{j \neq i}} d T+\left(\frac{\partial M}{\partial p}\right)_{T, x_{j \neq i}} d p-\sum_{i=1}^{C} x_{i} d \bar{M}_{i}=0 .
$$

In (16) $M$ is a general molar property, $x_{i}$ the molar fraction of component $i$ in the phase under consideration, $x_{j \neq i}$ the pertinent set of compositions, $C$ the number of components, and $\bar{M}_{i}$ the partial contribution of component $i$ to $M$.

When considering VLE, the molar excess Gibbs energy, $G^{E}$, can be evaluated from measurable $(T, p, x)$ data using activity coefficient relations. Replacing $M$ by $G^{E} / R T$ in the following equation yields the well-known relation

$$
-\frac{H_{m}^{E}}{R T^{2}} d T+\frac{V_{m}^{E}}{R T} d p-\sum_{i=1}^{C} x_{i} d \ln \gamma_{i}=0
$$

where $H_{m}^{E}$ and $V_{m}^{E}$ are the molar excess enthalpy and volume of mixing of the liquid phase. According to the thermodynamic principles, the activity coefficients $\gamma_{i}$ of the components were calculated from the expression as follows:

$$
Q=\frac{G^{E}}{R T}=\sum_{i=1}^{C} x_{i} \ln \gamma_{i}
$$

where $Q$ is the function of molar excess Gibbs energy and combining (17) and (18) yields

$$
d\left(\frac{G^{E}}{R T}\right)-\sum_{i=1}^{C} \ln \gamma_{i} d x_{i}=\sum_{i=1}^{C} x_{i} d \ln \gamma_{i}=-\frac{H_{m}^{E}}{R T^{2}} d T+\frac{V_{m}^{E}}{R T} d p .
$$

Application to a binary system gives

$$
d\left(\frac{G^{E}}{R T}\right)-\ln \frac{\gamma_{1}}{\gamma_{2}} d x_{1}=-\frac{H_{m}^{E}}{R T^{2}} d T+\frac{V_{m}^{E}}{R T} d p
$$

Simultaneous solution of (18) and (20) yields

$$
\begin{aligned}
& \ln \gamma_{1}=\frac{G^{E}}{R T}+x_{2}\left[\frac{d}{d x_{1}}\left(\frac{G^{E}}{R T}\right)+\frac{H_{m}^{E}}{R T^{2}} \frac{d T}{d x_{1}}-\frac{V_{m}^{E}}{R T} \frac{d p}{d x_{1}}\right], \\
& \ln \gamma_{2}=\frac{G^{E}}{R T}-x_{1}\left[\frac{d}{d x_{1}}\left(\frac{G^{E}}{R T}\right)+\frac{H_{m}^{E}}{R T^{2}} \frac{d T}{d x_{1}}-\frac{V_{m}^{E}}{R T} \frac{d p}{d x_{1}}\right] .
\end{aligned}
$$

Equation (18) substituted into (21) reduced it to

$$
\begin{gathered}
\gamma_{1}=\exp \left[Q+\left(1-x_{1}\right)\left(\frac{d Q}{d x_{1}}+\frac{H_{m}^{E}}{R T^{2}} \frac{d T}{d x_{1}}-\frac{V_{m}^{E}}{R T} \frac{d p}{d x_{1}}\right)\right], \\
\gamma_{2}=\exp \left[Q-x_{1}\left(\frac{d Q}{d x_{1}}+\frac{H_{m}^{E}}{R T^{2}} \frac{d T}{d x_{1}}-\frac{V_{m}^{E}}{R T} \frac{d p}{d x_{1}}\right)\right] .
\end{gathered}
$$

For a binary system comprised of species 1 and 2 at VLE state, at constant pressure, $\left(d p / d x_{1}\right)=0$, substitution into (22) reduced it to

$$
\gamma_{i}=\exp \left[Q+\left(1-x_{i}\right)\left[\left(\frac{d Q}{d x_{i}}\right)+\frac{H_{m}^{E}}{R T^{2}}\left(\frac{d T}{d x_{i}}\right)\right]\right], \quad(i=1,2) .
$$

The right-hand side, $\left(H_{m}^{E} / R T^{2}\right)\left(d T / d x_{i}\right)$, of (23) cannot be neglected. Proper use of (23) requires the availability 
TABLE 2: Antoine coefficients of the compounds and published parameters [36] used to calculate fugacity coefficients: critical temperature $T_{c}$, critical pressure $p_{c}$, critical volume $V_{c}$, critical compression $Z_{c}$, and acentric factor $\omega$ of pure compounds.

\begin{tabular}{lccccccrr}
\hline Compound & $A_{i}$ & $B_{i}$ & $C_{i}$ & $T_{c} / \mathrm{K}$ & $p_{c} / \mathrm{MPa}$ & $V_{c} / \mathrm{m}^{3} \cdot \mathrm{kmol}^{-1}$ & $Z_{c}$ & $\omega$ \\
\hline Methanol & 7.19736 & 1574.99 & -34.29 & 512.6 & 8.096 & 0.118 & 0.224 & 0.559 \\
Water & 7.07404 & 1657.46 & -46.13 & 647.3 & 22.048 & 0.056 & 0.229 & 0.344 \\
Ethanoic acid & 6.42452 & 1479.02 & -56.34 & 594.4 & 5.786 & 0.171 & 0.200 & 0.454 \\
\hline
\end{tabular}

of heats of mixing as a function of composition and temperature. The activity coefficients $\gamma_{i}$ of the components as functions of the excess Gibbs energy are as follows:

$$
\begin{gathered}
\gamma_{1}=\exp \left\{Q+\left(1-x_{1}\right)\left[\left(\frac{d Q}{d x_{1}}\right)+\frac{H_{m}^{E}}{R T^{2}}\left(\frac{d T}{d x_{1}}\right)\right]\right\}, \\
\gamma_{2}=\exp \left\{Q-x_{1}\left[\left(\frac{d Q}{d x_{1}}\right)+\frac{H_{m}^{E}}{R T^{2}}\left(\frac{d T}{d x_{1}}\right)\right]\right\} .
\end{gathered}
$$

From (14), this equation is rearranged to obtain

$$
y_{i}=\frac{x_{i} \gamma_{i} p_{i}^{s}}{\Phi_{i} p}
$$

Because $\sum y_{i}=1$, for the binary system, the equation may be summed to give

$$
\begin{aligned}
& \frac{x_{1} \gamma_{1} \varphi_{1}^{s} p_{1}^{s} \exp \left[V_{1}^{L}\left(p-p_{1}^{s}\right) / R T\right]}{\hat{\varphi}_{1}^{V} p} \\
&+\frac{x_{2} \gamma_{2} \varphi_{2}^{s} p_{2}^{s} \exp \left[V_{2}^{L}\left(p-p_{2}^{s}\right) / R T\right]}{\hat{\varphi}_{2}^{V} p}=1 .
\end{aligned}
$$

In (26), solved for $y_{i}$ by difference method. Suppose that $[0,1]$ is subdivided into $n$ subintervals $\left[x_{k}, x_{k+1}\right]$ of equal step size $h=1 / n$ by using $x_{k}=k h$ for $k=0,1, \ldots, n$. In $k$ difference point, we obtain

$$
\begin{aligned}
F_{k}= & -\left\{\frac{x_{1} \gamma_{1} \varphi_{1}^{s} p_{1}^{s} \exp \left[V_{1}^{L}\left(p-p_{1}^{s}\right) / R T\right]}{\hat{\varphi}_{1}^{V} p}\right\}_{k} \\
& -\left\{\frac{x_{2} \gamma_{2} \varphi_{2}^{s} p_{2}^{s} \exp \left[V_{2}^{L}\left(p-p_{2}^{s}\right) / R T\right]}{\hat{\varphi}_{2}^{V} p}\right\}_{k}=0 .
\end{aligned}
$$

Meanwhile, (23) may be shown as follows:

$$
\begin{aligned}
\left.y_{i}\right|_{k}=\exp \left\{Q_{k}+\left(1-\left.x_{i}\right|_{k}\right)[\right. & \frac{\left.Q\right|_{k+1}-\left.Q\right|_{k-1}}{2 / h} \\
& \left.\left.+\left.\frac{H_{m}^{E}}{R T^{2}}\left(\frac{d T}{d x_{1}}\right)\right|_{k}\right]\right\} .
\end{aligned}
$$

And (27) is linearized to obtain:

$$
\begin{aligned}
-F_{k}= & \left.\Delta Q\right|_{k-1}\left(\frac{\delta F_{k}}{\left.\delta Q\right|_{k-1}}\right) \\
& +\left.\Delta Q\right|_{k}\left(\frac{\delta F_{k}}{\left.\delta Q\right|_{k}}\right)+\left.\Delta Q\right|_{k+1}\left(\frac{\delta F_{k}}{\left.\delta Q\right|_{k+1}}\right) .
\end{aligned}
$$

The number of $n$ linear equation from (28) is solved for $\left.\Delta Q\right|_{k}$ by chasing method

$$
Q_{k}^{j+1}=Q_{k}^{j}+t \Delta Q_{k}^{j},
$$

where $t$ is relaxation factor, finally, $y_{i k}(k=1 \sim n)$ is obtained by difference method. The block diagram for calculation procedure was detailedly shown in Figure 2.

4.2. Calculation of Vapor-Phase Mole Fraction $y$ for the Binary Systems from Model. There are many methods concerning the correlation and prediction of VLE data. The model-free approach data treatment of vapor-liquid equilibrium is also one of the best strategies for the correlation and prediction of VLE data. Wisniak's group has developed that the novel model-free computation techniques and limiting conditions have been applied to VLE data for azeotropic systems [42]. Moreover, Segura and coworkers reported that a modelfree approach dealt with VLE data in application of ternary systems $[38,43]$. For the three binary systems of this study, the activity coefficients were correlated with the NRTL [39], Wilson [40], Margules [41], and van Laar [44] equations, respectively. The interaction parameters optimized were achieved by the objective function (OF) minimized using the least-squares fitting as follows:

$$
\mathrm{OF}=\sum_{i=1}^{N}\left(x_{i, \mathrm{cal}}-x_{i, \exp }\right)^{2}
$$

where $N$ is the number of experimental points $x_{i, \text { cal }}$ and $x_{i, \exp }$ are the liquid-phase mole fraction of component $i$ calculated and experimental values from the (12) or (13) and from measured data, respectively.

Because carboxylic acids are always present in an associated form, like a dimer or trimer, in both the vapor and liquid phases even at low pressures, a significant deviation in fugacity coefficient may exist using the ideal gas assumption. To illustrate the deviation from ideal behavior, Marek's chemical theory and HOC model were applied to deal with the associating component and modify the deviation from idealities of vapor phase [26-28], respectively. The Poynting correction factor was also included in the calculation of fugacity at the reference state. The liquid molar volumes were evaluated from the modified Rackett equation [37]. However, under isobaric conditions, the most volatile component cannot exist in the liquid state, only as superheated vapor. Hence, there is no way to calculate or measure this property for the molar volumes of the pure liquids. Therefore, the correct procedure for isobaric measurements is to calculate the overall values of $A_{i j}$ and $A_{i j}$, as adjustable parameters, 


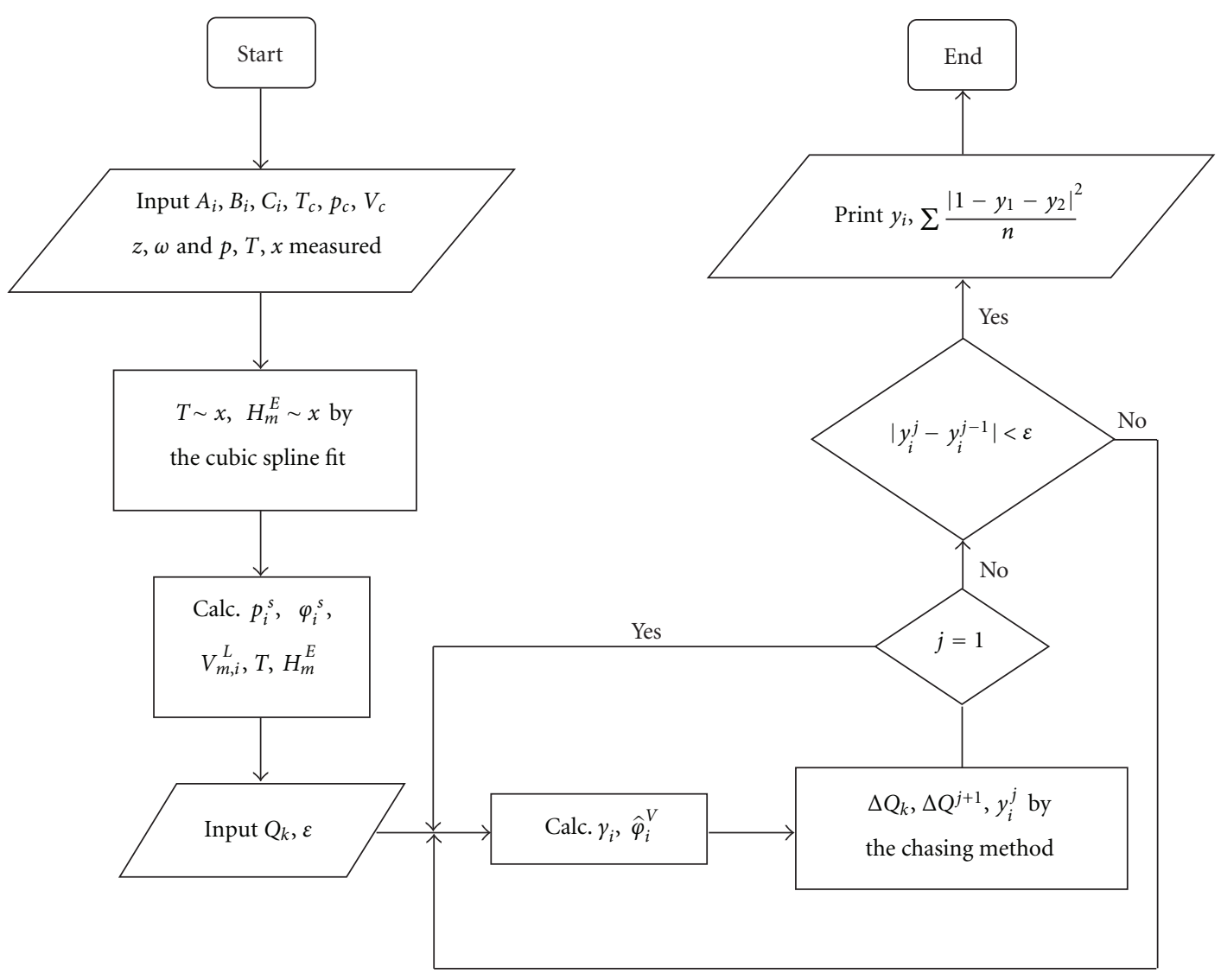

FIGURE 2: Block diagram for the calculation $y$ by $T, p, x$, and $H_{m}^{E}$.

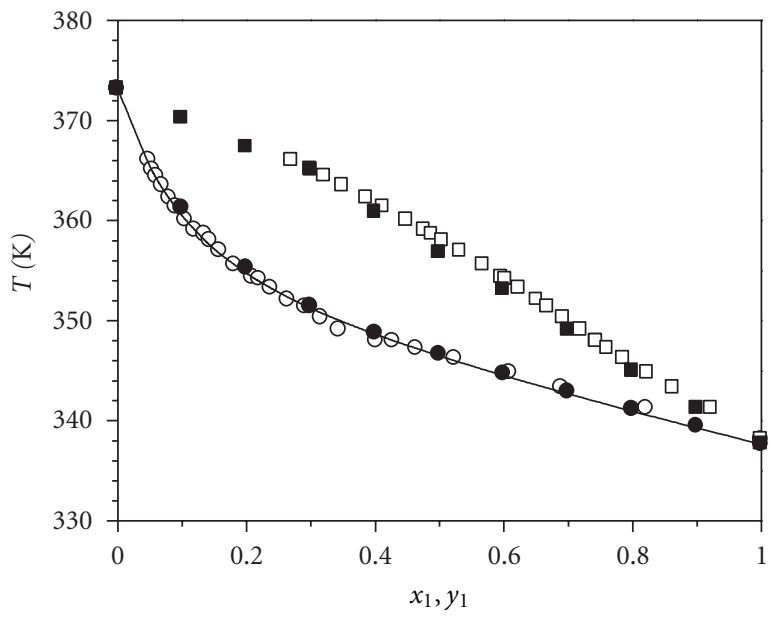

Figure 3: $T-x_{1}-y_{1}$ diagram for methanol (1) + water (2) at $101.325 \mathrm{kPa}: \square$, vapor-phase mole fraction $y_{1}$ from $T p x$ and $H_{m}^{E}$; $\mathbf{\square}$, vapor-phase mole fraction $y_{1}$ from the literature $[32,33]$; $\circ$, liquidphase experimental temperature; $\bullet$, liquid-phase mole fraction $x_{1}$ from the literature $[32,33]$; - , NRTL correlation temperature.

and not the values of the interaction excess energy. Hence, for Wilson model, $A_{i j}$ and $A_{i j}$ were reported as adjustable parameters.
The activity coefficients computed on the basis of NRTL model were used to evaluated dimensionless excess Gibbs function at $101.325 \mathrm{kPa}$ for three binary systems over the overall range of composition. Liquid-phase mole fraction $x_{1}$, experimental boiling point temperature $T_{\text {exp }}$, calculated bubble point temperature $T_{\text {cal }}$, vapor-phase mole fraction $y_{1}$ from the model, activity coefficients $\gamma_{1}$ and $\gamma_{2}$ using NRTL equation correlation, fugacity coefficients $\hat{\varphi}_{1}^{V}$ and $\hat{\varphi}_{2}^{V}$, and the molar excess enthalpies of mixing of the liquid phase $H_{m}^{E}$ are included in Table 3. The $T-x_{1}-y_{1}$ diagrams for the methanol (1) + water (2), methanol (1) + ethanoic acid (2), and water (1) + ethanoic acid (2) three binary systems at $101.325 \mathrm{kPa}$ are shown in Figures 3, 4, and 5, respectively. The plot of excess Gibbs energy function $G^{E} / R T$ versus liquid-phase mole fraction $x_{1}$ for the three binary systems is shown in Figure 6. All the mixtures exhibit deviations from ideality with a range that may be attributed to interactions leading to the formation of various associated aggregates. Observed nonideal behavior is indicative of the magnitude of experimental activity coefficients $\gamma_{i}$, as well as of the variation of excess Gibbs energy function, $G^{E} / R T$, with composition, as depicted in Figure 6. The obtained absolute maximum values of $G^{E} / R T$ for the methanol (1) + water (2), methanol (1) + ethanoic acid (2), and water (1) + ethanoic acid (2) three binary systems are $0.1703,0.0180$, and 0.0892 , respectively. The values of excess Gibbs energy 
TABle 3: VLE data for the methanol (1) + water (2), methanol (1) + ethanoic acid (2), and water (1) + ethanoic acid (2). Three binary systems at $101.325 \mathrm{kPa}$ : liquid-phase mole fraction $x_{1}$, experimental boiling point temperature $T_{\exp }$, calculated bubble point temperature $T_{\text {cal }}$, vapor-phase mole fraction $y_{1}$, activity coefficients $\gamma_{1}$ and $\gamma_{2}$ using NRTL equation correlation, fugacity coefficients $\hat{\varphi}_{1}^{V}$ and $\hat{\varphi}_{2}^{V}$, and molar excess enthalpies of mixing of the liquid phase $H_{m}^{E}$.

\begin{tabular}{|c|c|c|c|c|c|c|c|c|}
\hline$x_{1}$ & $T_{\exp } / \mathrm{K}$ & $T_{\mathrm{cal}} / \mathrm{K}$ & $y_{1}$ & $\gamma_{1}$ & $\hat{\varphi}_{1}^{V}$ & $\gamma_{2}$ & $\hat{\varphi}_{2}^{V}$ & $H_{m}^{E} / \mathrm{J} \cdot \mathrm{mol}^{-1}$ \\
\hline \multicolumn{9}{|c|}{ Methanol (1) + water (2) } \\
\hline 0.0000 & 373.15 & 373.15 & 0.0000 & & & 1.0000 & 0.9882 & 0.00 \\
\hline 0.0484 & 366.00 & 365.54 & 0.2704 & 2.1436 & 0.9852 & 1.0034 & 0.9875 & 225.74 \\
\hline 0.0539 & 365.05 & 364.88 & 0.3009 & 2.1147 & 0.9849 & 1.0042 & 0.9875 & 248.74 \\
\hline 0.0607 & 364.40 & 364.12 & 0.3213 & 2.0799 & 0.9846 & 1.0053 & 0.9874 & 276.88 \\
\hline 0.0696 & 363.50 & 363.19 & 0.3492 & 2.0358 & 0.9843 & 1.0069 & 0.9874 & 312.53 \\
\hline 0.0806 & 362.25 & 362.13 & 0.3866 & 1.9835 & 0.9839 & 1.0092 & 0.9873 & 354.36 \\
\hline 0.0911 & 361.35 & 361.21 & 0.4126 & 1.9360 & 0.9836 & 1.0117 & 0.9872 & 392.94 \\
\hline 0.1056 & 360.05 & 360.05 & 0.4492 & 1.8739 & 0.9832 & 1.0155 & 0.9871 & 443.59 \\
\hline 0.1197 & 359.05 & 359.04 & 0.4762 & 1.8172 & 0.9829 & 1.0197 & 0.9870 & 489.29 \\
\hline 0.1354 & 358.60 & 358.02 & 0.4885 & 1.7584 & 0.9826 & 1.0248 & 0.9869 & 538.32 \\
\hline 0.1436 & 358.00 & 357.53 & 0.5047 & 1.7293 & 0.9824 & 1.0277 & 0.9869 & 562.20 \\
\hline 0.1586 & 356.95 & 356.70 & 0.5323 & 1.6788 & 0.9822 & 1.0334 & 0.9868 & 602.83 \\
\hline 0.1815 & 355.55 & 355.56 & 0.5677 & 1.6083 & 0.9819 & 1.0428 & 0.9867 & 659.52 \\
\hline 0.2092 & 354.35 & 354.35 & 0.5969 & 1.5325 & 0.9815 & 1.0555 & 0.9865 & 719.43 \\
\hline 0.2202 & 354.10 & 353.91 & 0.6031 & 1.5049 & 0.9814 & 1.0609 & 0.9865 & 741.25 \\
\hline 0.2380 & 353.25 & 353.24 & 0.6237 & 1.4633 & 0.9812 & 1.0701 & 0.9864 & 772.62 \\
\hline 0.2648 & 352.05 & 352.32 & 0.6519 & 1.4066 & 0.9809 & 1.0847 & 0.9862 & 812.77 \\
\hline 0.2918 & 351.35 & 351.48 & 0.6681 & 1.3561 & 0.9807 & 1.1005 & 0.9861 & 846.82 \\
\hline 0.3166 & 350.30 & 350.76 & 0.6923 & 1.3148 & 0.9805 & 1.1157 & 0.9860 & 870.15 \\
\hline 0.3442 & 349.05 & 350.02 & 0.7197 & 1.2740 & 0.9803 & 1.1336 & 0.9859 & 889.06 \\
\hline 0.4015 & 347.95 & 348.61 & 0.7431 & 1.2038 & 0.9800 & 1.1730 & 0.9856 & 909.80 \\
\hline 0.4282 & 347.90 & 348.00 & 0.7443 & 1.1767 & 0.9798 & 1.1924 & 0.9854 & 911.28 \\
\hline 0.4644 & 347.20 & 347.21 & 0.7613 & 1.1449 & 0.9796 & 1.2194 & 0.9853 & 903.04 \\
\hline 0.5240 & 346.20 & 345.98 & 0.7860 & 1.1026 & 0.9793 & 1.2656 & 0.9850 & 869.55 \\
\hline 0.6091 & 344.80 & 344.33 & 0.8231 & 1.0595 & 0.9789 & 1.3338 & 0.9845 & 783.83 \\
\hline 0.6899 & 343.31 & 342.85 & 0.8633 & 1.0325 & 0.9785 & 1.3995 & 0.9840 & 666.92 \\
\hline 0.8213 & 341.20 & 340.56 & 0.9221 & 1.0086 & 0.9779 & 1.5038 & 0.9832 & 419.31 \\
\hline 1.0000 & 338.10 & 337.66 & 1.0000 & 1.0000 & 0.9771 & & & 0.00 \\
\hline \multicolumn{9}{|c|}{ Methanol (1) + ethanol acid (2) } \\
\hline 0.0000 & 390.15 & 391.04 & 0.0000 & & & 1.0000 & 0.9703 & 0.00 \\
\hline 0.0359 & 387.32 & 386.23 & 0.1574 & 0.9388 & 0.9765 & 0.9999 & 0.9685 & 77.28 \\
\hline 0.0410 & 386.21 & 385.56 & 0.1664 & 0.9393 & 0.9768 & 0.9999 & 0.9682 & 86.70 \\
\hline 0.0648 & 383.89 & 382.68 & 0.2719 & 0.9419 & 0.9779 & 0.9997 & 0.9666 & 134.05 \\
\hline 0.0741 & 382.73 & 381.90 & 0.3133 & 0.9428 & 0.9782 & 0.9996 & 0.9660 & 149.55 \\
\hline 0.0859 & 381.20 & 380.60 & 0.3333 & 0.9441 & 0.9787 & 0.9995 & 0.9652 & 171.14 \\
\hline 0.1040 & 380.03 & 379.06 & 0.3830 & 0.9460 & 0.9791 & 0.9992 & 0.9639 & 205.37 \\
\hline 0.1280 & 378.46 & 377.35 & 0.4602 & 0.9485 & 0.9797 & 0.9988 & 0.9622 & 245.43 \\
\hline 0.1629 & 375.62 & 374.70 & 0.5213 & 0.9521 & 0.9802 & 0.9981 & 0.9595 & 299.80 \\
\hline 0.1919 & 373.21 & 372.43 & 0.5873 & 0.9551 & 0.9805 & 0.9973 & 0.9572 & 341.32 \\
\hline 0.2510 & 369.31 & 368.44 & 0.6495 & 0.9609 & 0.9808 & 0.9954 & 0.9528 & 411.44 \\
\hline 0.3391 & 364.35 & 363.56 & 0.7538 & 0.9692 & 0.9809 & 0.9916 & 0.9461 & 490.73 \\
\hline 0.4401 & 358.54 & 357.71 & 0.8232 & 0.9776 & 0.9805 & 0.9857 & 0.9388 & 536.56 \\
\hline 0.5829 & 351.77 & 350.75 & 0.8999 & 0.9874 & 0.9797 & 0.9748 & 0.9292 & 526.43 \\
\hline 0.7050 & 346.47 & 346.39 & 0.9389 & 0.9936 & 0.9790 & 0.9633 & 0.9217 & 449.37 \\
\hline 0.7509 & 344.90 & 344.06 & 0.9533 & 0.9955 & 0.9787 & 0.9583 & 0.9189 & 401.45 \\
\hline 0.8109 & 342.81 & 342.35 & 0.9693 & 0.9974 & 0.9783 & 0.9515 & 0.9155 & 330.61 \\
\hline 0.8711 & 341.60 & 340.75 & 0.9766 & 0.9988 & 0.9779 & 0.9442 & 0.9122 & 241.41 \\
\hline 0.9161 & 339.65 & 340.00 & 0.9859 & 0.9995 & 0.9776 & 0.9384 & 0.9097 & 163.78 \\
\hline 1.0000 & 338.15 & 337.66 & 1.0000 & 1.0000 & 0.9771 & & & 0.00 \\
\hline
\end{tabular}


TABle 3: Continued.

\begin{tabular}{|c|c|c|c|c|c|c|c|c|}
\hline$x_{1}$ & $T_{\exp } / \mathrm{K}$ & $T_{\text {cal }} / \mathrm{K}$ & $y_{1}$ & $\gamma_{1}$ & $\hat{\varphi}_{1}^{V}$ & $\gamma_{2}$ & $\hat{\varphi}_{2}^{V}$ & $H_{m}^{E} / \mathrm{J} \cdot \mathrm{mol}^{-1}$ \\
\hline \multicolumn{9}{|c|}{ Water (1) + ethanoic acid (2) } \\
\hline 0.0000 & 390.15 & 391.04 & 0.0000 & & & 1.0000 & 0.9703 & 0.00 \\
\hline 0.0665 & 387.22 & 387.67 & 0.1140 & 1.4161 & 0.9899 & 1.0025 & 0.9693 & 245.31 \\
\hline 0.0749 & 387.00 & 387.31 & 0.1288 & 1.4046 & 0.9898 & 1.0031 & 0.9692 & 273.17 \\
\hline 0.0855 & 386.48 & 386.88 & 0.1603 & 1.3903 & 0.9897 & 1.0040 & 0.9691 & 307.50 \\
\hline 0.0995 & 385.86 & 386.34 & 0.1938 & 1.3722 & 0.9896 & 1.0054 & 0.9689 & 350.32 \\
\hline 0.1507 & 384.16 & 384.60 & 0.2802 & 1.3117 & 0.9892 & 1.0121 & 0.9683 & 489.63 \\
\hline 0.1722 & 383.44 & 383.96 & 0.3155 & 1.2888 & 0.9891 & 1.0156 & 0.9681 & 540.35 \\
\hline 0.1926 & 382.99 & 383.39 & 0.3375 & 1.2684 & 0.9890 & 1.0193 & 0.9679 & 585.57 \\
\hline 0.2168 & 382.39 & 382.77 & 0.3676 & 1.2458 & 0.9890 & 1.0242 & 0.9677 & 632.34 \\
\hline 0.2502 & 381.53 & 381.98 & 0.4101 & 1.2171 & 0.9889 & 1.0316 & 0.9674 & 689.92 \\
\hline 0.2936 & 380.94 & 381.06 & 0.4407 & 1.1838 & 0.9887 & 1.0425 & 0.9670 & 750.61 \\
\hline 0.3303 & 380.20 & 380.36 & 0.4815 & 1.1589 & 0.9887 & 1.0528 & 0.9667 & 788.98 \\
\hline 0.3756 & 379.40 & 379.57 & 0.5253 & 1.1318 & 0.9886 & 1.0666 & 0.9663 & 821.39 \\
\hline 0.4465 & 378.27 & 378.48 & 0.5890 & 1.0965 & 0.9885 & 1.0908 & 0.9658 & 841.59 \\
\hline 0.4946 & 377.61 & 377.82 & 0.6274 & 1.0768 & 0.9885 & 1.1087 & 0.9654 & 836.35 \\
\hline 0.5615 & 376.80 & 376.99 & 0.6777 & 1.0543 & 0.9884 & 1.1355 & 0.9649 & 802.60 \\
\hline 0.6036 & 376.24 & 376.51 & 0.7137 & 1.0427 & 0.9884 & 1.1533 & 0.9645 & 767.63 \\
\hline 0.6517 & 375.59 & 376.00 & 0.7546 & 1.0315 & 0.9884 & 1.1746 & 0.9642 & 714.78 \\
\hline 0.7067 & 375.11 & 375.46 & 0.7849 & 1.0213 & 0.9884 & 1.1998 & 0.9637 & 639.01 \\
\hline 0.7045 & 375.11 & 375.48 & 0.7848 & 1.0217 & 0.9884 & 1.1988 & 0.9638 & 642.76 \\
\hline 0.7507 & 374.71 & 375.05 & 0.8173 & 1.0148 & 0.9883 & 1.2207 & 0.9634 & 568.24 \\
\hline 0.8008 & 374.31 & 374.62 & 0.8501 & 1.0091 & 0.9883 & 1.2451 & 0.9630 & 475.20 \\
\hline 0.8723 & 373.80 & 374.05 & 0.9011 & 1.0035 & 0.9883 & 1.2809 & 0.9624 & 323.52 \\
\hline 0.9116 & 373.54 & 373.76 & 0.9315 & 1.0016 & 0.9883 & 1.3009 & 0.9620 & 230.13 \\
\hline 0.9546 & 373.24 & 373.45 & 0.9630 & 1.0004 & 0.9883 & 1.3231 & 0.9616 & 121.95 \\
\hline 1.0000 & 373.15 & 373.15 & 1.0000 & 1.0000 & 0.9882 & & & 0.00 \\
\hline
\end{tabular}

TABLE 4: Correlation parameters for activity coefficients, average deviation for studied systems and vapor-phase composition mean absolute deviation from the literatures.

\begin{tabular}{|c|c|c|c|c|}
\hline Equation & Parameters or deviations & Methanol (1) + water (2) & Methanol (1) + ethanoic acid (2) & Water (1) + ethanoic acid (2) \\
\hline \multirow{5}{*}{ NRTL $^{\mathrm{a}}$} & $\left(g_{12}-g_{11}\right) / \mathrm{J} \cdot \mathrm{mol}^{-1}$ & -436.50 & -85.50 & -352.42 \\
\hline & $\left(g_{21}-g_{22}\right) / \mathrm{J} \cdot \mathrm{mol}^{-1}$ & 1159.55 & 0.98 & 715.43 \\
\hline & $\alpha_{12}$ & 0.241 & 0.30 & 0.23 \\
\hline & $d T / \mathrm{K}$ & 0.28 & 0.51 & 0.33 \\
\hline & $d y$ & 0.0072 & 0.0054 & 0.0096 \\
\hline \multirow{4}{*}{ Wilson $^{\mathrm{a}}$} & $\Lambda_{12} / \mathrm{J} \cdot \mathrm{mol}^{-1}$ & 389.37 & 50.46 & 644.71 \\
\hline & $\Lambda_{21} / \mathrm{J} \cdot \mathrm{mol}^{-1}$ & 368.45 & 95.58 & -87.59 \\
\hline & $d T / \mathrm{K}$ & 0.43 & 0.47 & 0.64 \\
\hline & $d y$ & 0.0036 & 0.0059 & 0.0053 \\
\hline \multirow{4}{*}{ Margules $^{\mathrm{b}}$} & $A_{12}$ & 0.95 & 0.12 & 0.29 \\
\hline & $A_{21}$ & 0.65 & -0.46 & 0.57 \\
\hline & $d T / \mathrm{K}$ & 0.37 & 0.32 & 0.56 \\
\hline & $d y$ & $0.0049(0.0057)^{\mathrm{c}}$ & $0.0075(0.0234)^{\mathrm{c}}$ & $0.0086(0.0123)^{\mathrm{c}}$ \\
\hline \multirow{4}{*}{ van Laarb } & $A_{12}$ & 0.86 & 0.24 & 0.32 \\
\hline & $A_{21}$ & 0.56 & 0.03 & 0.55 \\
\hline & $d T / \mathrm{K}$ & 0.27 & 0.58 & 0.47 \\
\hline & $d y$ & 0.0069 & 0.0078 & 0.0098 \\
\hline
\end{tabular}

${ }^{a}$ Wilson's interaction parameters $\left(\mathrm{J} \cdot \mathrm{mol}^{-1}\right)$, NRTL's interaction parameters $\left(\mathrm{J} \cdot \mathrm{mol}^{-1}\right) .{ }^{\mathrm{b}}$ Margules and van Laar interaction parameters (dimensionless). $d T=\sum\left|T_{\exp }-T_{\text {cal }}\right| / N ; N$ : number of data points; $T_{\text {cal }}$ : calculated bubble point from model, $\mathrm{K} ; T_{\text {exp }}$ : experimental boiling point temperature, $\mathrm{K}$. $d y=\sum\left|y_{\text {cal }}-y_{\text {mod }}\right| / N ; N$ : number of data points; $y_{\text {cal }}$ : calculated vapor-phase mole fraction from $T p x ; y_{\text {mol }}$ : calculated vapor-phase mole fraction from model. ${ }^{c}$ The values in parentheses from the literatures [38-41]. 
function $G^{E} / R T$ are positive for methanol (1) + water (2) and water (1) + ethanoic acid (2) binary systems. However, for methanol (1) + ethanoic acid (2) system, the values of those are negative in the overall range of mole fraction. $G^{E} / R T$ values follow the order methanol $(1)+$ water $(2)>$ water (1) + ethanoic acid (2) > methanol (1) + ethanoic acid (2). The absolute maximum value of $G^{E} / R T$ is approximate at an equimolar fraction in three binary systems. Figures 3-5 show that the comparison of the predicted vapor-phase and experimental liquid-phase compositions with those of the literature $[10,11,32,33]$. Comparing with the values of vaporphase and liquid-phase component from the literatures, the values of those from the paper are in good agreement with the literature, as shown in Figures 3-5. The results have demonstrated that the methods for $T p x$ and $H_{m}^{E}$ are appropriate for representing the experimental data of the three binary systems. The optimum model interaction parameter of liquid activity coefficient and the absolute average deviations for the different models, and from $T p x$ and $H_{m}^{E}$ are listed in Table 4. Herein, we obtained the results by the four different types of correlations for the prediction of activity coefficients in these systems, which reveal that the deviations of NRTL, Wilson, Margules, and van Laar equations are reasonably small in Table 4 . For comparison, the mean deviations obtained by Gmehling and Onken [32, 33, 45, 46] are also shown in the Table 4 . It can seem that two sets of deviation values are comparable. Since the superiority of one method over the others is not always obvious, practice must rely on experience and analogy. The comprehensive comparisons of four of the methods (NRTL, Wilson, van Laar, and Margules) were made in Table 4. From the data analysis, the temperature deviations between the experimental and calculated values of four different types of model are very similar in the three binary systems, and the vapor-phase mole fraction deviations between calculated values from $T p x$ and $H_{m}^{E}$, and from the model are very similar. Therefore, the activity coefficient models are appropriate for representing the experimental data of the three binary systems. In Table 4, the absolute average deviations $d T$ of the difference between boiling point temperature from experiment and bubbling point temperature from calculation by NRLT model parameters for the three binary systems are $0.28^{\circ} \mathrm{C}, 0.51^{\circ} \mathrm{C}$, and $0.33^{\circ} \mathrm{C}$, respectively. And the absolute average deviations $d y$ of the difference between vapor-phase mole fraction from $T p x$ and $H_{m}^{E}$ calculation and from NRTL model calculation are $0.0072,0.0054$, and 0.0096 , respectively.

4.3. Correlation and Prediction of VLE of Ternary System. The binary interaction parameters of the NRTL, Wilson, Margules, and van Laar model given in Table 4 were used to correlate and predict the VLE data of the ternary system. VLE data for methanol (1) + water (2) + ethanoic acid (3) at $101.325 \mathrm{kPa}$ included liquid-phase mole fraction $x_{1}$, $x_{2}$, and $x_{3}$, experimental boiling point temperature $T_{\exp }$, calculated bubble point temperature $T_{\text {cal }}$, calculated vaporphase mole fraction $y_{1}, y_{2}$, and $y_{3}$, activity coefficients $\gamma_{1}, \gamma_{2}$, and $\gamma_{3}$, the average deviation in the bubble temperatures of the ternary system using NRTL equation correlation listed in Table 5. The absolute average and maximum deviation

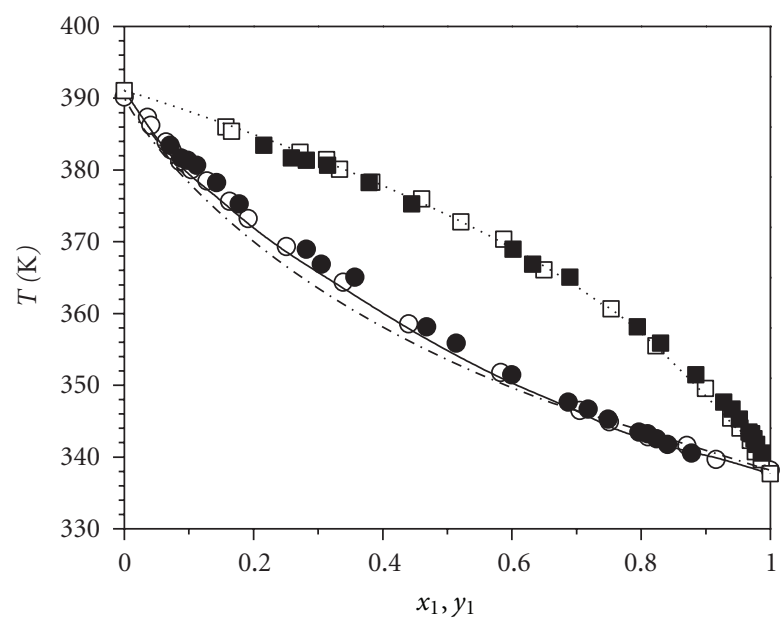

FIgURE 4: $T-x_{1}-y_{1}$ diagram for methanol (1) + ethanoic acid (2) at $101.325 \mathrm{kPa}: \square$, vapor-phase mole fraction $y_{1}$ from $T p x$ and $H_{m}^{E} ; \mathbf{\square}$, vapor-phase mole fraction $y_{1}$ from literature [10]; - , dot line, vapor-phase mole fraction $y_{1}$ with Block diagram for the calculation $y$ by $T, p, x$, and $H_{m}^{E}$ neglected from our previous work [15]; ○, liquid-phase experimental temperature; •, liquid-phase experimental temperature from literature $[10] ;-\cdots \cdot$, dash dot, liquid-phase experimental temperature from our previous work [15]; - NRTL correlation temperature.



Figure 5: $T-x_{1}-y_{1}$ diagram for water (1) + ethanoic acid (2) at $101.325 \mathrm{kPa}: \square$, vapor-phase mole fraction $y_{1}$ from $T p x$ and $H_{m}^{E}$; $\boldsymbol{\square}$, vapor-phase mole fraction $y_{1}$ from literature [11]; $\bullet$, liquidphase experimental temperature from the literature; $\circ$, liquid-phase experimental temperature [11]; -, NRTL correlation temperature.

between the boiling point from experimental data and the bubble point from NRTL model calculation are $0.77^{\circ} \mathrm{C}$ and $1.94^{\circ} \mathrm{C}$, respectively. The average and maximum deviations using Wilson, Margules, and van Laar equation individually are $0.79^{\circ} \mathrm{C}, 1.90^{\circ} \mathrm{C}, 0.85^{\circ} \mathrm{C}, 1.89^{\circ} \mathrm{C}$, and $0.96^{\circ} \mathrm{C}, 1.91^{\circ} \mathrm{C}$. Diagram of VLE for the ternary system methanol (1) + water (2) + ethanoic acid (3) at $101.325 \mathrm{kPa}$ is shown in Figure 7. 
TABle 5: VLE data for the methanol (1) + water (2) + ethanoic acid (3) Ternary system at $101.325 \mathrm{kPa}$ : liquid-phase mole fraction $x_{1}, x_{2}$, and $x_{3}$, experimental boiling point temperature $T_{\exp }$, calculated bubble point temperature $T_{\text {cal }}$, vapor-phase mole fraction $y_{1}, y_{2}$, and $y_{3}$, activity coefficients $\gamma_{1}, \gamma_{2}$, and $\gamma_{3}$ using NRTL equation correlation.

\begin{tabular}{|c|c|c|c|c|c|c|c|c|c|c|}
\hline$x_{1}$ & $x_{2}$ & $x_{3}$ & $T_{\exp } / \mathrm{K}$ & $T_{\text {cal }} / \mathrm{K}$ & $y_{1}$ & $y_{2}$ & $y_{3}$ & $\gamma_{1}$ & $\gamma_{2}$ & $\gamma_{3}$ \\
\hline 0.7919 & 0.2080 & 0.0001 & 341.08 & 340.94 & 0.9108 & 0.0870 & 0.0022 & 1.0152 & 1.5155 & 0.9163 \\
\hline 0.7502 & 0.1967 & 0.0531 & 342.79 & 342.12 & 0.9024 & 0.0882 & 0.0094 & 1.0156 & 1.5068 & 0.9294 \\
\hline 0.6923 & 0.1816 & 0.1261 & 344.60 & 343.90 & 0.8886 & 0.0872 & 0.0242 & 1.0147 & 1.4953 & 0.9444 \\
\hline 0.6623 & 0.1841 & 0.1536 & 345.45 & 344.77 & 0.8783 & 0.0910 & 0.0307 & 1.0152 & 1.4838 & 0.9493 \\
\hline 0.5917 & 0.1645 & 0.2438 & 348.36 & 347.27 & 0.8561 & 0.0895 & 0.0544 & 1.0114 & 1.4719 & 0.9632 \\
\hline 0.4619 & 0.4554 & 0.0827 & 349.12 & 348.30 & 0.7566 & 0.2242 & 0.0191 & 1.1037 & 1.2749 & 0.9612 \\
\hline 0.4122 & 0.3196 & 0.2682 & 350.38 & 352.17 & 0.7339 & 0.1929 & 0.0732 & 1.0461 & 1.3352 & 0.9808 \\
\hline 0.5333 & 0.1483 & 0.3184 & 350.67 & 349.55 & 0.8338 & 0.0881 & 0.0781 & 1.0072 & 1.4623 & 0.9722 \\
\hline 0.4263 & 0.4203 & 0.1534 & 351.53 & 350.19 & 0.7359 & 0.2254 & 0.0387 & 1.0874 & 1.2853 & 0.9763 \\
\hline 0.4946 & 0.1375 & 0.3679 & 351.93 & 351.19 & 0.8167 & 0.0869 & 0.0964 & 1.0040 & 1.4558 & 0.9772 \\
\hline 0.3166 & 0.4774 & 0.2060 & 352.84 & 354.29 & 0.6481 & 0.2893 & 0.0627 & 1.1178 & 1.2310 & 1.0116 \\
\hline 0.3959 & 0.3903 & 0.2138 & 353.19 & 351.89 & 0.7162 & 0.2258 & 0.0580 & 1.0733 & 1.2939 & 0.9847 \\
\hline 0.2537 & 0.5812 & 0.1651 & 354.90 & 355.93 & 0.5880 & 0.3565 & 0.0555 & 1.1972 & 1.1675 & 1.0536 \\
\hline 0.2148 & 0.6454 & 0.1398 & 356.16 & 357.08 & 0.5479 & 0.4013 & 0.0508 & 1.2669 & 1.1308 & 1.0932 \\
\hline 0.1750 & 0.4020 & 0.4230 & 363.36 & 363.66 & 0.4673 & 0.3513 & 0.1814 & 1.0664 & 1.2364 & 1.0246 \\
\hline 0.0585 & 0.9055 & 0.0360 & 364.18 & 364.83 & 0.2965 & 0.6797 & 0.0238 & 1.9547 & 1.0150 & 1.5148 \\
\hline 0.1563 & 0.3589 & 0.4848 & 365.42 & 365.67 & 0.4367 & 0.3420 & 0.2213 & 1.0459 & 1.2516 & 1.0186 \\
\hline 0.0478 & 0.9228 & 0.0294 & 366.09 & 365.86 & 0.2627 & 0.7164 & 0.0209 & 2.0514 & 1.0104 & 1.5759 \\
\hline 0.1413 & 0.3246 & 0.5341 & 366.99 & 367.35 & 0.4109 & 0.3321 & 0.2570 & 1.0318 & 1.2630 & 1.0145 \\
\hline 0.0404 & 0.9348 & 0.0248 & 367.10 & 366.66 & 0.2359 & 0.7454 & 0.0187 & 2.1259 & 1.0077 & 1.6231 \\
\hline 0.0350 & 0.9435 & 0.0215 & 367.41 & 367.30 & 0.2142 & 0.7689 & 0.0169 & 2.1843 & 1.0059 & 1.6602 \\
\hline 0.1290 & 0.2963 & 0.5747 & 368.56 & 368.80 & 0.3888 & 0.3218 & 0.2895 & 1.0214 & 1.2720 & 1.0116 \\
\hline 0.0241 & 0.9592 & 0.0167 & 368.82 & 368.78 & 0.1626 & 0.8230 & 0.0144 & 2.2986 & 1.0032 & 1.7357 \\
\hline 0.0203 & 0.9657 & 0.0140 & 369.63 & 369.35 & 0.1425 & 0.8449 & 0.0126 & 2.3510 & 1.0023 & 1.7687 \\
\hline 0.0175 & 0.9704 & 0.0121 & 370.14 & 369.79 & 0.1266 & 0.8622 & 0.0112 & 2.3906 & 1.0017 & 1.7938 \\
\hline 0.0154 & 0.9740 & 0.0106 & 370.54 & 370.13 & 0.1141 & 0.8759 & 0.0100 & 2.4220 & 1.0013 & 1.8136 \\
\hline 0.0884 & 0.2313 & 0.6803 & 371.87 & 373.49 & 0.3017 & 0.3004 & 0.3979 & 1.0004 & 1.2864 & 1.0068 \\
\hline 0.0779 & 0.2038 & 0.7183 & 373.44 & 375.08 & 0.2771 & 0.2814 & 0.4415 & 0.9933 & 1.2933 & 1.0050 \\
\hline 0.0690 & 0.1805 & 0.7505 & 375.20 & 376.50 & 0.2548 & 0.2629 & 0.4822 & 0.9878 & 1.2987 & 1.0037 \\
\hline 0.0625 & 0.1635 & 0.7740 & 375.65 & 377.59 & 0.2376 & 0.2480 & 0.5144 & 0.9841 & 1.3022 & 1.0030 \\
\hline 0.0413 & 0.1802 & 0.7785 & 379.37 & 379.33 & 0.1656 & 0.2871 & 0.5473 & 0.9859 & 1.2885 & 1.0044 \\
\hline 0.0359 & 0.1567 & 0.8074 & 379.87 & 380.59 & 0.1486 & 0.2617 & 0.5897 & 0.9812 & 1.2942 & 1.0032 \\
\hline 0.0314 & 0.1369 & 0.8317 & 381.03 & 381.69 & 0.1338 & 0.2380 & 0.6282 & 0.9775 & 1.2986 & 1.0023 \\
\hline 0.0280 & 0.1222 & 0.8498 & 381.64 & 382.55 & 0.1220 & 0.2192 & 0.6588 & 0.9749 & 1.3016 & 1.0018 \\
\hline
\end{tabular}

\section{Conclusions}

VLE data for the ternary system methanol + water + ethanoic acid and three constituent binary systems at $101.325 \mathrm{kPa}$ : methanol + water, methanol + ethanoic acid, and water + ethanoic acid were determined at different liquid-phase compositions using a novel pump ebulliometer. The equilibrium composition of the vapor phase was calculated from $T, p$, $x$, and $H_{m}^{E}$ based on the $Q$ function of excess Gibbs free energy by the indirect method. The experimental data were correlated using the NRTL, Wilson, Margules, and van Laar equations. It was shown that the deviations of NRTL, Wilson, Margules, and van Laar equations are reasonably small. The VLE data of ternary system were predicted by NRTL, Wilson, Margules, and van Laar equation. The calculated bubble points accorded well with the experimental data. The results show that the calculated bubble point is fitted by the models, which satisfy the need for the design and operation of separation process in chemical industry. Moreover, the method will provide theoretical guidance for the research of VLE data of strongly associating system of vapor and liquid phase in nonideal behavior. 


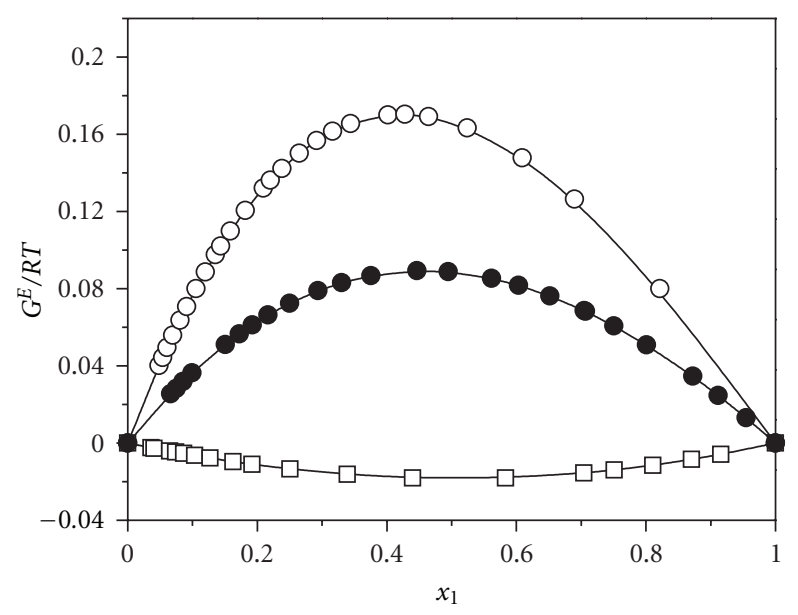

FIgure 6: Excess Gibbs energy functions $\left(G^{E} / R T\right)$ versus liquidphase mole fraction of component $1\left(x_{1}\right)$ diagram: $\circ$, methanol (1) + water (2); •, water (1) + ethanoic acid (2); $\square$, methanol (1) + ethanoic acid (2).

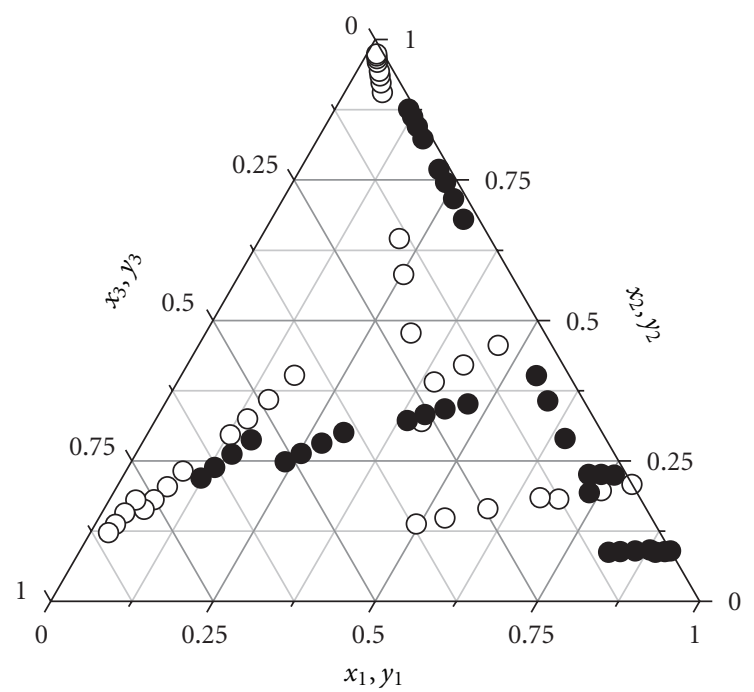

Figure 7: Diagram of VLE for the ternary system methanol (1) + water (2) + ethanoic acid (3) at $101.325 \mathrm{kPa}: \circ$, liquid-phase mole fraction; $\bullet$, vapor-phase mole fraction.

\section{Acknowledgments}

This work was supported by the Deutscher Akademischer Austausch Dienst (DAAD) (Ref. Code: A/11/06441), the National Natural Science Foundation of China (Grant no. 21075026), and the Natural Science Foundation of the Higher Education Institutions of Anhui Province (Grant no. ZD200902).

\section{References}

[1] J. J. Ljunglin and H. C. van Ness, "Calculation of vapour-liquid equilibria from vapour pressure data," Chemical Engineering Science, vol. 17, no. 7, pp. 531-539, 1962.

[2] E. Hala, J. Pick, V. Fried, and O. Vilim, Vapor-Liquid Equilibrium, Pergamon, New York, NY, USA, 1958.
[3] H. C. Van Ness, "On the integration of the coexistence equation for binary vapor-liquid equilibrium," AIChE Journal, vol. 16, no. 1, pp. 18-22, 1970.

[4] F. O. Mixon, B. Gumowski, and B. H. Carpenter, "Computation of vapor-liquid equilibrium data from solution vapor pressure measurements," Industrial and Engineering Chemistry Fundamentals, vol. 4, no. 4, pp. 455-459, 1965.

[5] J. A. Barker, "Determination of activity coefficients from total pressure measurements," Australian Journal of Chemistry, vol. 6, no. 3, pp. 207-210, 1953.

[6] L. C. Tao, "How to compute binary vapor-liquid equilibrium compositions from experimental $P-x$ or $t-x$ data," Industrial and Engineering Chemistry, vol. 53, no. 4, pp. 307-309, 1961.

[7] J. M. Prausnitz, T. Anderson, E. Grens, C. Eckert, R. Hsieh, and J. P. O. 'Connell, Computer Calculations For Multicomponent Vapor-Liquid and Liquid-Liquid Equilibria, Prentice-Hall, Englewood Cliffs, NJ, USA, 1980.

[8] W. Arlt, "A new apparatus for phase equilibria in reacting mixtures," Fluid Phase Equilibria, vol. 158-160, pp. 973-977, 1999.

[9] Z. P. Xu and K. T. Chuang, "Correlation of vapor-liquid equilibrium data for methyl acetate methanol-water-acetic acid mixtures," Industrial and Engineering Chemistry Research, vol. 36, no. 7, pp. 2866-2870, 1997.

[10] H. Sawistowski and P. A. Pilavakis, "Vapor-liquid equilibrium with association in both phases. Multicomponent systems containing acetic acid," Journal of Chemical and Engineering Data, vol. 27, no. 1, pp. 64-71, 1982.

[11] W. Chang, G. Guan, X. Li, and H. Yao, "Isobaric vapor-liquid equilibria for water + acetic acid + (n-pentyl acetate or isopropyl acetate)," Journal of Chemical and Engineering Data, vol. 50, no. 4, pp. 1129-1133, 2005.

[12] C. Zhang, H. Wan, L. Xue, and G. Guan, "Investigation on isobaric vapor liquid equilibrium for acetic acid+water+(npropyl acetate or iso-butyl acetate)," Fluid Phase Equilibria, vol. 305, no. 1, pp. 68-75, 2011.

[13] Q. Xie, H. Wan, M. Han, and G. Guan, "Investigation on isobaric vapor-liquid equilibrium for acetic acid + water + methyl ethyl ketone + isopropyl acetate," Fluid Phase Equilibria, vol. 280, no. 1-2, pp. 120-128, 2009.

[14] W. Chang, H. Wan, G. Guan, and H. Yao, "Isobaric vaporliquid equilibria for water + acetic acid $+(\mathrm{N}$-methyl pyrrolidone or N-methyl acetamide)," Fluid Phase Equilibria, vol. 242, no. 2, pp. 204-209, 2006.

[15] D. Gao, D. Zhu, H. Sun, L. Zhang, H. Chen, and J. Si, “Isobaric vapor-liquid equilibria for binary and ternary mixtures of methanol, ethanoic acid, and propanoic acid," Journal of Chemical and Engineering Data, vol. 55, no. 9, pp. 4002-4009, 2010.

[16] D. Gao, D. Zhu, L. Zhang et al., "Isobaric vapor-liquid equilibria for binary and ternary mixtures of propanal, propanol, and propanoic acid," Journal of Chemical and Engineering Data, vol. 55, no. 12, pp. 5887-5895, 2010.

[17] A. Tamir and J. Wisniak, "Vapour-liquid equilibria in associating solutions," Chemical Engineering Science, vol. 30, no. 3, pp. 335-342, 1975.

[18] A. Apelblat and F. Kohler, "Excess Gibbs energy of methanol + propionic acid and of methanol + butyric acid," The Journal of Chemical Thermodynamics, vol. 8, no. 8, pp. 749-756, 1976.

[19] A. Rius, J. L. Otero, and A. Macarron, "Equilibres liquidevapeur de mélanges binaires donnantune réaction chimique: systèmes méthanol-acide acétique; éthanol-acide acétique; $n$ propanol-acide acétique; n-butanol-acide acétique," Chemical Engineering Science, vol. 10, no. 1-2, pp. 105-111, 1959. 
[20] Z. H. Wang, B. Wu, J. W. Zhu, K. Chen, and W. Q. Wang, "Isobaric vapor-liquid-liquid equilibrium for isopropenyl acetate plus water plus acetic acid at $101 \mathrm{kPa}$," Fluid Phase Equilibria, vol. 314, no. 2, pp. 152-155, 2012.

[21] S. Bernatová, K. Aim, and I. Wichterle, "Isothermal vapourliquid equilibrium with chemical reaction in the quaternary water + methanol + acetic acid + methyl acetate system, and in five binary subsystems," Fluid Phase Equilibria, vol. 247, no. 1-2, pp. 96-101, 2006.

[22] A. Tamir and J. Wisniak, "Association effects in ternary vapour-liquid equilibria," Chemical Engineering Science, vol. 31, no. 8, pp. 625-630, 1976.

[23] A. Tamir and J. Wisniak, "Vapor equilibrium in associating systems (water-formic acid-propionic acid)," Industrial and Engineering Chemistry Fundamentals, vol. 15, no. 4, pp. 274280, 1976.

[24] A. Tamir and J. Wisniak, "Activity coefficient calculations in multicomponent associating systems," Chemical Engineering Science, vol. 33, no. 6, pp. 651-656, 1978.

[25] J. Wisniak and A. Tamir, "Vapor-liquid equilibria in the ternary systems water-formic acid-acetic acid and water-acetic acid-propionic acid," Journal of Chemical and Engineering Data, vol. 22, no. 3, pp. 253-260, 1977.

[26] J. Marek and G. Standart, "Vapor-liquid equilibria in mixtures containing an associating substance. I. Equilibrium relationships for systems with an associating component," Collection of Czechoslovak Chemical Communications, vol. 19, pp. 10741084, 1954.

[27] J. Marek, "Vapor-liquid equilibria in mixtures containing an associating substance. II. Binary mixtures of acetic acid at atmospheric pressure," Collection of Czechoslovak Chemical Communications, vol. 20, pp. 1490-1502, 1955.

[28] J. G. Hayden and J. P. O'Conell, "A generalized method for predicting second virial coefficient," Industrial \& Engineering Chemistry Process Design and Development, vol. 14, no. 3, pp. 209-215, 1975.

[29] J. A. Riddick, W. B. Bunger, and T. K. Sakano, Organic Solvents: Physical Properties and Methods of Purification, Wiley-Interscience, New York, NY, USA, 4th edition, 1986.

[30] M. V. P. Rao and P. R. Naidu, "Excess volumes of binary mixtures of alcohols in methylcohexane," Canadian Journal of Chemistry, vol. 52, no. 5, pp. 788-790, 1974.

[31] Z. M. Qiu, Z. C. Luo, and Y. Hu, "The pump ebullionmeter," Journal of Chemical Engineering of Chinese Universities, vol. 11, no. 1, pp. 74-77, 1997.

[32] J. Gmehling and U. Onken, Vapor-Liquid Equilibrium Data Collection-Aqueous Organic Systems, vol. 1, part 1 of DECHEMA Chemistry Data Series, DECHEMA, Frankfurt, Germany, 1977.

[33] J. Gmehling and U. Onken, Vapor-Liquid Equilibrium Data Collection-Organic Hydroxy Compounds: Alcohols, vol. 1, part 2 of DECHEMA Chemistry Data Series, DECHEMA, Frankfurt, Germany, 1977.

[34] R. Francesconi and F. Comelli, "Liquid-phase enthalpy of mixing for the system 1,3-dioxolane-chlorobenzene in the temperature range 288.15-313.15 K," Journal of Chemical and Engineering Data, vol. 31, no. 2, pp. 250-252, 1986.

[35] J. Gmehling, "Excess enthalpies for 1,1,1-trichloroethane with alkanes, ketones, and esters," Journal of Chemical and Engineering Data, vol. 38, no. 1, pp. 143-146, 1993.

[36] J. Shi, J. D. Wang, and G. Z. Yu, Handbook of Chemical Engineering, Chemical Industry Press, Beijing, China, 2nd edition, 1996.
[37] C. Tsonopoulos, "An empirical correlation of second virial coefficients," AIChE Journal, vol. 20, no. 2, pp. 263-272, 1974.

[38] E. Lam, A. Mejía, H. Segura, J. Wisniak, and S. Loras, "A model-free approach data treatment of vapor-liquid equilibrium data in ternary systems. 1. Theory and numerical procedures," Industrial and Engineering Chemistry Research, vol. 40, no. 9, pp. 2134-2148, 2001.

[39] H. Renon and J. M. Prausnitz, "Estimation of parameters for the NRTL equation for excess gibbs energies of strongly nonideal liquid mixtures," Industrial \& Engineering Chemistry Process Design and Development, vol. 8, no. 3, pp. 413-419, 1969.

[40] G. M. Wilson, "Vapor-liquid equilibrium. XI. A new expression for the excess free energy of mixing," Journal of the American Chemical Society, vol. 86, no. 2, pp. 127-130, 1964.

[41] M. S. Margules, "On the composition of saturated vapors of mixtures," Akademie der Wissenschaften in Wien, Mathematisch-Naturwissenschaftliche Klasse Abteilung II, vol. 104, pp. 1234-1239, 1895.

[42] J. Wisniak, A. Apelblat, and H. Segura, "Application of modelfree computation techniques and limiting conditions for azeotropy. An additional assessment of experimental data," Chemical Engineering Science, vol. 52, no. 23, pp. 4393-4402, 1997.

[43] E. Lam, A. Mejía, H. Segura, J. Wisniak, and S. Loras, "A model-free approach data treatment of vapor-liquid equilibrium data in ternary systems. 2. Applications," Industrial and Engineering Chemistry Research, vol. 40, no. 9, pp. 2149-2159, 2001.

[44] J. J. van Laar, "The vapor pressure of binary mixtures," Zeitschrift für Physikalische Chemie, vol. 72, pp. 723-751, 1910.

[45] J. Gmehling and U. Onken, Vapor-Liquid Equilibrium Data Collection-Carboxylic Acids, Anhydrides, Esters, vol. 1, part 5 of DECHEMA Chemistry Data Series, DECHEMA, Frankfurt, Germany, 1977.

[46] J. Gmehling and U. Onken, Vapor-Liquid Equilibrium Data Collection-Organic Hydroxy Compounds: Alcohols (Supplement 3), vol. 1, part 2 of DECHEMA Chemistry Data Series, DECHEMA, Frankfurt, Germany, 1977. 



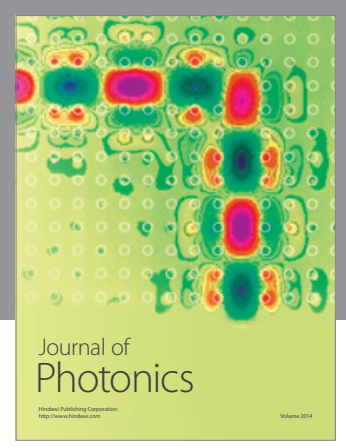

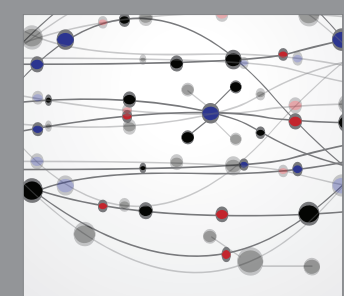

The Scientific World Journal
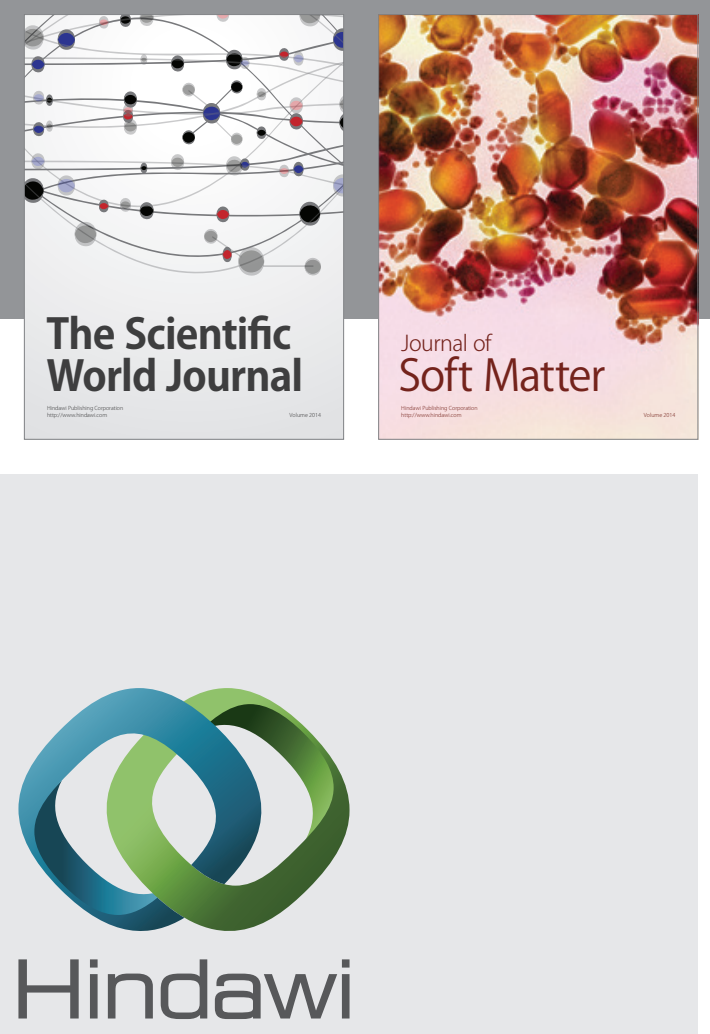

Submit your manuscripts at

http://www.hindawi.com
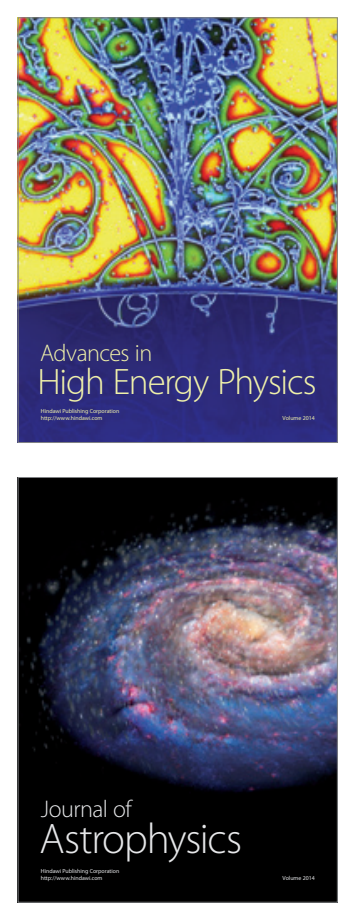
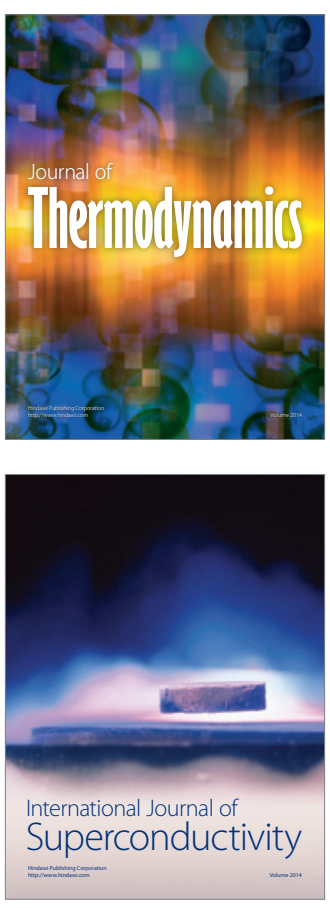
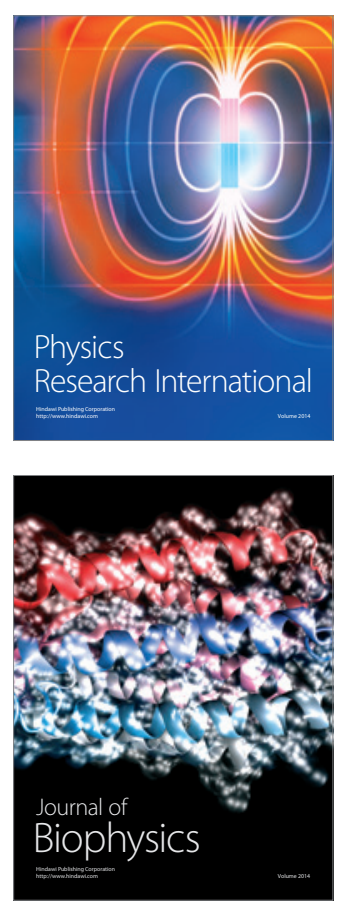
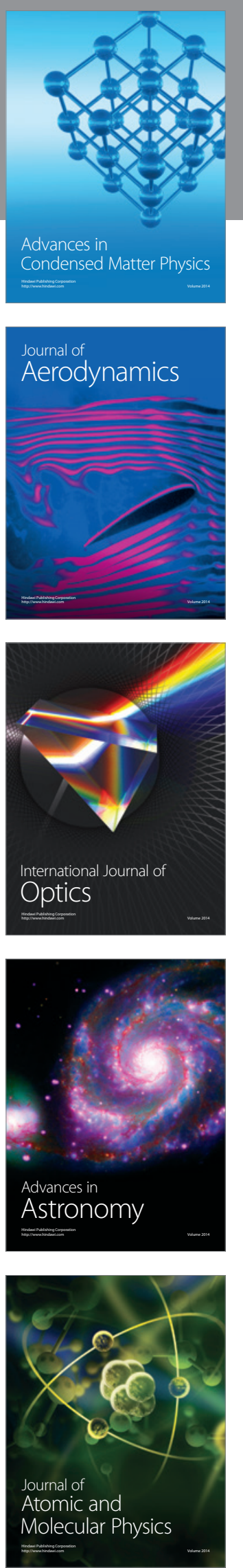